\title{
Barriers to Providing VTE Chemoprophylaxis to Hospitalized Patients: A Nursing-Focused Qualitative Evaluation
}

\author{
Lindsey Kreutzer, MPH, Anthony D Yang, MD, MS, Christina Sansone, MPH, Christina Minami, MD, \\ Lily Saadat, MD, Karl Y Bilimoria, MD, MS, Julie K Johnson, MSPH, PhD*
}

Feinberg School of Medicine, Northwestern University, Chicago, Illinois.

BACKGROUND: Venous thromboembolism (VTE) is a serious medical condition that results in preventable morbidity and mortality.

OBJECTIVES: The objective of this study was to identify nursing-related barriers to administration of VTE chemoprophylaxis to hospitalized patients.

DESIGN: This was a qualitative study including nurses from five inpatient units at one hospital.

METHODS: Observations were conducted on five units to gain insight into the process for administering chemoprophylaxis. Focus group interviews were conducted with nurses and were audio-recorded, transcribed verbatim, and analyzed using the Theoretical Domains Framework to identify barriers to providing VTE chemoprophylaxis.
RESULTS: We conducted 14 focus group interviews with nurses from five inpatient units to assess nurses' perceptions of barriers to administration of VTE chemoprophylaxis. The barriers identified included nurses' misconceptions that ambulating patients did not require chemoprophylaxis, nurses' uncertainty when counseling patients on the importance of chemoprophylaxis, and a lack of comparative data for nurses regarding their specific refusal rates.

CONCLUSIONS: Multiple factors act as barriers to patients receiving VTE chemoprophylaxis. These barriers are often modifiable targets for quality improvement. There is a need to focus on behavior changes that will remove or minimize barriers and equip nurses to ensure administration of VTE chemoprophylaxis by engaging patients in their care. Journal of Hospital Medicine 2019;14:668-672. (C) 2019 Society of Hospital Medicine
V enous thromboembolism (VTE), comprising deep venous thrombosis and pulmonary embolism (PE), ${ }^{1}$ is a serious medical condition that results in preventable morbidity and mortality. ${ }^{1-5}$ VTE affects all age groups, all races/ethnicities, and both genders, but there are known factors that increase the risk of developing VTE (eg, advanced age, undergoing surgery, hospitalization, and immobility). ${ }^{1-3,5-7}$ Prevention of VTE among hospitalized patients is of paramount importance to avoid preventable death, chronic illness/long-term complications, ${ }^{8}$ longer hospital stays, and increased hospital costs. ${ }^{9}$ Fortunately, there is clear evidence that provision of appropriate prophylaxis can decrease the risk of a VTE event occurring, and broadly accepted best-practice guidelines reflect this evidence. ${ }^{3,5}$

Given the inadequacy of current VTE-related quality measures to identify actionable failures in the provision of VTE prophylaxis, our group created a VTE process-of-care measure to

Corresponding Author: Julie K. Johnson, MSPH, PhD; E-mail: julie.k.johnson@ northwestern.edu; Telephone: 312-503-3823

Published online first August 21, 2019.

Find Additional Supporting Information in the online version of this article.

Received: March 1, 2019; Revised: July 8, 2019; Accepted: July 16, 2019

(c) 2019 Society of Hospital Medicine DOI 10.12788/jhm.3290 assess adherence to the components of VTE prophylaxis: (1) early ambulation, (2) mechanical prophylaxis (sequential compression devices [SCDs]), and (3) chemoprophylaxis administered at the correct dose and frequency for the duration of the patient's hospital stay.,10,11 This quality measure was conceived, created, and iteratively revised to measure whether optimal care is provided to patients throughout their hospitalization and identify actionable areas in which failures of care occur, in order to decrease the risk of a VTE event. Data from our institution provided evidence that while ambulation and SCD component measure adherence is high, chemoprophylaxis adherence required significant improvement. ${ }^{10}$ When chemoprophylaxis process measure adherence data were analyzed further, a major failure mode was patient refusal of one or more doses. However, the drivers of patient refusal are not well defined in the literature, and previous studies have called for a greater focus on developing interventions to improve VTE chemoprophylaxis administration. ${ }^{12}$

Previous research has shown that nurses can influence patient compliance with VTE prophylaxis..$^{13-15}$ A mixed-methods study by Elder et al. found that nurses in units with high rates of failure to provide optimal chemoprophylaxis offered the medication as optional, leading researchers to conclude that nurses perceived chemoprophylaxis as discretionary. ${ }^{13}$ Another study by Lee et al., conducted a survey of bedside registered nurses and identified nurses' lack of education on VTE prevention as a 
significant barrier to providing care. ${ }^{14}$ These studies show that multiple levels of influence impact how nurses provide VTE chemoprophylaxis, particularly when they encounter patients who refuse chemoprophylaxis.

To explore the nuance and interplay of multiple influences, we used the Theoretical Domains Framework (TDF), an integrative framework that applies theoretical approaches to interventions aimed at behavior change. ${ }^{15-18}$ The framework contains 14 interrelated domains that characterize the behavior being studied, in this case, administration of VTE chemoprophylaxis. Consequently, we designed a nurse-focused, qualitative evaluation with the objective to identify nursing-related barriers to administration of VTE chemoprophylaxis.

\section{METHODS}

\section{Inpatient Unit Selection}

The study team accessed data from the hospital's Enterprise Data Warehouse to review patient refusal rates of VTE chemoprophylaxis for each inpatient unit in the hospital. Patient refusal was utilized as a proxy measure for the behavior of nurses attempting to administer VTE chemoprophylaxis. Of the 14 medical and surgical units in the hospital, two medical and two surgical units were selected to participate in the qualitative evaluation based on having the highest patient refusal rates. One unit (surgical) was also selected to serve as a benchmark because it had the lowest patient refusal rate. Table 1 includes the refusal rates for the five units. Given the low refusal rate for the best performing unit, we suspected that it would be possible to decrease the patient refusal rate for other units with similar patient populations and interprofessional teams at the institution.

\section{Observations}

We observed chemoprophylaxis administration on the five units to understand the process for ordering and administering chemoprophylaxis. An observation protocol was utilized to document the date, time, and location of the observation as well as descriptive notes including accounts of particular events. ${ }^{19,20}$ Observations occurred in May 2016 and informed the creation of a process map outlining the procedure for ordering and administering VTE chemoprophylaxis. The process map was utilized to create the focus group interview guide and ensure the interview guide included pertinent questions for each step of the process (Appendix A).

\section{Focus Group Interviews}

We conducted focus group interviews with day and night shift nurses on the five units to assess nurses' understanding of VTE chemoprophylaxis and nurses' perceptions of barriers to administration of VTE chemoprophylaxis. The study team chose to conduct focus group interviews in an effort to maximize participation and to speak with multiple nurses within a shorter period of time. The focus group structure allowed the study team to speak with nurses during their shifts, as one could briefly step out, if required, for patient care and return to rejoin the discussion.
TABLE 1. Unit-Level Refusal Rates for VTE Chemoprophylaxis

\begin{tabular}{|c|c|}
\hline Unit & Refusal Rate $\mathrm{a}^{\mathrm{a}}$ \\
\hline \multicolumn{2}{|c|}{ Surgical Inpatient Units } \\
\hline 1 & $9.9 \%$ \\
\hline 2 & $6.1 \%$ \\
\hline \multicolumn{2}{|c|}{ Medical Inpatient Units } \\
\hline 3 & $24.9 \%$ \\
\hline 4 & $21.8 \%$ \\
\hline \multicolumn{2}{|c|}{ Benchmark Unit (Surgical) } \\
\hline 5 & $1.9 \%$ \\
\hline
\end{tabular}

aDecember 2015-February 2016

Abbreviations: VTE, venous thromboembolism.

We developed a semistructured interview guide ${ }^{21}$ with questions focused on identifying nurses' perceptions of guideline-recommended care for VTE chemoprophylaxis, where they learned these guidelines, how nurses discuss chemoprophylaxis with patients, how they handle the conversation with patients who refuse, and if there are times when chemoprophylaxis is not necessary. The interview guide was vetted by a multidisciplinary team consisting of clinical nursing coordinators and nurse managers from medical and surgical units, hospital quality leaders, surgeons and general internists, and qualitative research experts. The interview guide is included as Appendix B.

The unit clinical coordinators and nurse managers identified dates and times for the focus groups that would be minimally disruptive to the unit. For each of the four units with a high patient refusal rate, two focus groups were conducted during the lunch hour and one was conducted at the end of the night shift to ensure that both day and night shift nurses were included in the study. Two focus groups were conducted with the best-practice unit during the lunch hour. For each focus group, the clinical coordinator identified two to eight nurses who could step away from patient care to participate or who had completed their shifts. In total, approximately 67 nurses participated in the focus groups.

The focus groups ( $n=14$ ) lasted approximately 40 minutes during May and June 2016. Two members of the study team cofacilitated interviews, which were recorded and transcribed verbatim.

\section{Coding and Data Analysis}

To develop the code book, the study team, consisting of three qualitative researchers, independently read one focus group transcript and applied the TDF domains to the nurses' perceptions of barriers to administration of VTE chemoprophylaxis. ${ }^{21-24}$ In addition to coding by domain, the study team also coded nursing perceptions as barriers or facilitators. The study 
TABLE 2. Theoretical Domains, Framework Domains, Definitions, and Illustrative Quotes for Relevant Theoretical Domains and Framework Domains

\begin{tabular}{|c|c|c|c|}
\hline Domain & $\begin{array}{l}\text { Definition } \\
\text { (adapted from Cane } \\
\text { et } \text { al. }^{14} \text { ) }\end{array}$ & $\begin{array}{l}\text { Rationale for Domain } \\
\text { Choice }\end{array}$ & Quotes Illustrative of Barriers \\
\hline Knowledge & $\begin{array}{l}\text { An awareness of the } \\
\text { existence of something }\end{array}$ & $\begin{array}{l}\text { Lack of knowledge on } \\
\text { guidelines }\end{array}$ & $\begin{array}{l}\text { "Most of them [patients] I'll push for them to take the shot unless I do see them like actively walking } \\
\text { around." - Nurse, U4 } \\
\text { "... sometimes I see a patient walking laps, like } 30 \text { times around the station... maybe they don't need it } \\
\text { [chemoprophylaxis]" - Nurse U4 }\end{array}$ \\
\hline \multirow[t]{2}{*}{$\begin{array}{l}\text { Environmental context } \\
\text { and resources }\end{array}$} & \multirow{2}{*}{$\begin{array}{l}\text { Any circumstance of } \\
\text { a person's situation } \\
\text { or environment that } \\
\text { discourages or encourages } \\
\text { the development of skills } \\
\text { and abilities, independence, } \\
\text { social competence, and } \\
\text { adaptive behavior }\end{array}$} & $\begin{array}{l}\text { Educational materials not } \\
\text { easily accessible within } \\
\text { nurses' workflow }\end{array}$ & $\begin{array}{l}\text { "...I know we've got the patient things... like the leaflets and the little booklets that we can print off... } \\
\text { I haven't physically printed one off (laughs)." - Nurse, U3 }\end{array}$ \\
\hline & & $\begin{array}{l}\text { Perceived patient pain of } \\
\text { chemoprophylaxis injections } \\
\text { as a main deterrent for } \\
\text { patient compliance }\end{array}$ & $\begin{array}{l}\text { "make the heparin stop burning...they [patients] always want to ask, can you put it through the IV, like no, } \\
\text { I got to poke you..." - Nurse, U2 } \\
\text { "... it stinks that they [heparin injections]...two of them fall over night shift, so it's like we're giving them one } \\
\text { right before they go to sleep and then right when they wake up." - Nurse, U1 }\end{array}$ \\
\hline Skill & $\begin{array}{l}\text { An ability or proficiency } \\
\text { acquired through practice }\end{array}$ & $\begin{array}{l}\text { Lack of skills to persuade } \\
\text { patients to comply }\end{array}$ & $\begin{array}{l}\text { "... if it's a patient who's not moving around, I usually try to be a little bit more, not aggressive but just kind } \\
\text { of explain the benefits and what could be the risks of not taking it, but if it's someone that's up and that's } \\
\text { moving around, usually okay... be sure that you're doing your walks..." -Nurse, U4 } \\
\text { "... actually sometimes they'll [patients] say 'I thought I told you to have that taken off my [chart], why do } \\
\text { people keep asking me' and, you know, so then it makes it harder ... to feel comfortable asking them time } \\
\text { and time again." - Nurse, U3 }\end{array}$ \\
\hline Beliefs about capabilities & $\begin{array}{l}\text { Acceptance of the truth, } \\
\text { reality, or validity about } \\
\text { an ability, talent, or facility } \\
\text { that a person can put to } \\
\text { constructive use }\end{array}$ & $\begin{array}{l}\text { Lack of data on current } \\
\text { practice or performance in } \\
\text { comparison with others }\end{array}$ & $\begin{array}{l}\text { "They'd be like 'no, it hurts my arm' and I'd be like okay and wouldn't really put up a fight, but then I realized } \\
\text { that like a quarter of my patients were refusing." - Nurse, U1 } \\
\text { "I always offer it to them unless you know I have to give it to them twice and the first time they're like } \\
\text { adamantly like 'no, no, no ... I'm walking in the hallways. Then the second time maybe not but no matter } \\
\text { what usually I'll offer it and then very rarely would I just not bring it in if it's ordered." - Nurse, U4 }\end{array}$ \\
\hline
\end{tabular}

team reviewed the coded transcript and reconciled any differences in coding. This process was repeated for a second transcript, and then all remaining transcripts were assigned to two out of three study team members for coding, with the entire study team meeting to reconcile any differences. If necessary, the team member who did not code a transcript acted as the tie-breaker if there were discrepancies in codes that could not be reconciled.

Once coding was completed, we identified the TDF domains that were most relevant to the administration of VTE chemoprophylaxis. ${ }^{16}$ Member checking (testing the analysis, interpretations, and conclusions with members of those groups from whom the data were originally obtained) was performed with the four clinical nursing coordinators and four nurse managers from the participating units to establish face validity of the themes identified from the focus group interviews. ${ }^{25}$

The study team used MaxQDA, V12 (Berlin, Germany) to support data coding and analysis. ${ }^{26}$ The Northwestern University institutional review board office deemed this project research on nonhuman-subjects because it focused on the process of providing VTE chemoprophylaxis and not about the patients themselves. The purpose of the study was explained at the beginning of each focus group, and nurses gave verbal consent to have the focus group recorded.

\section{RESULTS}

We conducted 14 focus groups with day and night shift nurses from five units (two medical and three surgical) at a single insti- tution. All nurses invited to participate in a focus group agreed to participate. The data were coded and grouped by domain and identified as barriers or facilitators. The findings included below are for the domains most relevant to the provision of VTE prophylaxis. Table 2 provides illustrative verbatim quotes for each domain that was represented in the focus groups.

\section{THEORETICAL DOMAINS FRAMEWORK DOMAINS}

\section{Knowledge}

All interviewees recognized that providing some form of prophylaxis to mitigate the risk of a VTE event is essential. Some nurses stated that seeing a patient ambulating meant they would consider not administering prescribed chemoprophylaxis, while others would try to negotiate with patients by asking the patient to allow one dose of chemoprophylaxis prescribed two to three times daily because it was better than receiving no doses.

\section{Environmental Context and Resources}

Multiple barriers to providing optimal care were associated with the environmental context and a lack of resources. There was a lack of accessible, comprehensive, patient-centered education materials on VTE chemoprophylaxis to supplement a nurse's explanation about the importance of chemoprophylaxis. Furthermore, many nurses cited the perceived patient pain of chemoprophylaxis injections as the main deterrent to patient compliance, especially subcutaneous heparin injections, 
which occur up to three times in 24 hours and often cause more pain at the site of injection than low-molecular-weight heparin. Nurses felt that transitioning patients from receiving subcutaneous heparin injections to receiving low-molecular-weight heparin could be a main driver to reduce patient refusals.

\section{Skills}

Nurses felt inadequately equipped to handle patient refusals. Many said that patient refusal of treatments was never discussed in nursing school. As a result, when patients refused treatments, the nurses did not know how to handle the situation. They felt that they lacked the tools and techniques to persuade the patient to comply.

\section{Beliefs about Capabilities}

Nurses did not know their own patient refusal rate or benchmarks of an acceptable refusal rate in contrast to one that is too high. Without this feedback, they were unable to assess their own behavior or performance related to providing VTE chemoprophylaxis.

\section{DISCUSSION}

Nurses play a critical role in providing VTE chemoprophylaxis to patients throughout their hospitalization. This study provided a unique opportunity to perform an in-depth, qualitative analysis of the barriers nurses face in providing patients with VTE chemoprophylaxis as part of their daily work caring for patients. We discovered several nursing-related barriers to the provision of VTE chemoprophylaxis, including lack of knowledge, resources, skill, and misconceptions of their capability to provide VTE chemoprophylaxis. We used a bottom-up approach by incorporating the voices of unit nurses, clinical coordinators, and nurse managers to understand potential barriers. Our findings brought to light the challenge of delivering standardized care in an area of care that is generally agreed upon, yet not fully followed. Some nurses display greater proficiency than others at communicating with patients who do not understand their risk for VTE and need for chemoprophylaxis. Furthermore, there is a pronounced misconception around the delivery of VTE chemoprophylaxis. Nurses have the inaccurate belief that even if ordered, chemoprophylaxis is not required. This misconception was widespread among nurses taking care of both medical and surgical patients. These factors appear to be modifiable targets for quality improvement and highlight the need for a skillsbased education during the new hire onboarding process, as well as ongoing reeducation to ensure nursing staff have the skills to appropriately provide best-practice care for VTE chemoprophylaxis. Nurses felt ownership of the results of the qualitative evaluation because they were included in every aspect from the beginning. ${ }^{27}$ This sense of ownership will support future quality improvement efforts to develop a skills-based intervention to improve the provision of VTE chemoprophylaxis. ${ }^{18,27}$

This study has certain limitations. First, it was a qualitative study assessing nursing-related barriers to providing VTE chemoprophylaxis at a single institution, and the results cannot be generalized broadly. However, the techniques and results are transferable to other hospital settings and other clinical care situations. Thus, we believe that other institutions can utilize our methods and that similar lessons can be learned and applied. Furthermore, the validity of our study is bolstered by concordance between the results of this study and those of other studies conducted on the topic of provision of VTE prophylaxis by nurses. ${ }^{13-15,21}$ Other studies utilized observations and surveys to determine potential nurse-related barriers to the provision of VTE prophylaxis, such as lack of knowledge and the belief that the need for prophylaxis can be determined based on whether or not the patient is ambulating; $;^{13,14}$ however, by utilizing focus group interviews, we allowed nurses to speak in their own voices about their experiences with VTE prophylaxis, and we were able to delve deeper and identify additional barriers that emerged from discussions with nurses, such as the lack of skill and misconceptions of capability. ${ }^{28,29}$ Second, the study focused solely on nurses. Additional initiatives are underway to assess the roles of resident physicians, attending physicians, and patients in the provision of VTE prophylaxis.

Nursing-related barriers to the provision of VTE chemoprophylaxis include a lack of knowledge, resources, skills, and misconceptions of the consequences of missed elements of VTE prophylaxis. Future initiatives will focus on equipping nurses to have meaningful conversations with patients and engaging patients in their care through development of a multifaceted bundle of interventions. Furthermore, similar methods of qualitative inquiry will be used to identify the role of resident and attending physicians and patients in the provision of VTE chemoprophylaxis.

\section{Acknowledgments}

The authors thank Sonali Oberoi, Joanne Prinz, Nancy Tomaska, and Kate Paredes, as well as all the nurses who participated in focus group interviews for this study and the nurse managers and clinical coordinators who helped to schedule the focus group interviews.

Disclosures: The authors declare that they have no competing interests.

Funding: This study was funded by the Surgical Outcomes and Quality Improvement Center at Northwestern University.

\section{References}

1. Beckman MG, Hooper WC, Critchley SE, Ortel TL. Venous thromboembolism: a public health concern. Am J Prev Med. 2010;38(4):S495-S501. https:// doi.org/10.1016/j.amepre.2009.12.017.

2. Falck-Ytter Y, Francis CW, Johanson NA, et al. Prevention of VTE in orthopedic surgery patients: Antithrombotic Therapy and Prevention of Thrombosis, 9th ed: American College of Chest Physicians evidence-based clinical practice guidelines. Chest. 2012;141(2):e278S-e325S. https://doi.org/10.1378/ chest.11-2404

3. Gould MK, Garcia DA, Wren SM, et al. Prevention of VTE in nonorthopedic surgical patients: antithrombotic therapy and prevention of thrombosis: American College of Chest Physicians evidence-based clinical practice guidelines. Chest. 2012;141(2):e227S-e277S. https://doi.org/10.1378/ chest.11-2297.

4. Guyatt GH, Akl EA, Crowther M, et al. Executive summary: antithrombotic therapy and prevention of thrombosis: American College of Chest Physicians evidence-based clinical practice guidelines. Chest. 2012;141(2):7S-47S. https://doi.org/10.1378/chest.1412S3.

5. Office of the Surgeon General. National Heart L, and Blood Institute. The Surgeon General's Call to Action to Prevent Deep Vein Thrombosis and Pulmonary Embolism. Rockville, MD; 2008.

6. Geerts WH, Pineo GF, Heit JA, et al. Prevention of venous thromboembo- 
lism: the Seventh ACCP Conference on Antithrombotic and Thrombolytic Therapy. Chest. 2004;126(3):338S-400S. https://doi.org/10.1378/chest.126.3_ suppl.338S

7. Haut ER, Lau BD, Kraus PS, et al. Preventability of hospital-acquired venous thromboembolism. JAMA Surg. 2015;150(9):912-915. https://doi. org/10.1001/jamasurg.2015.1340.

8. Kahn SR, Solymoss S, Lamping DL, Abenhaim L. Long-term outcomes after deep vein thrombosis: postphlebitic syndrome and quality of life. J Gen Intern Med. 2000;15(6):425-429. https://doi.org/10.1046/j.15251497.2000.06419.x

9. Mahan CE, Holdsworth MT, Welch SM, Borrego M, Spyropoulos AC. Deepvein thrombosis: a United States cost model for a preventable and costly adverse event. Thromb Haemost. 2011;106(3):405-415. https://doi.org/10.1160/ TH11-02-0132.

10. Kinnier CV, Ju MH, Kmiecik T, et al. Development of a novel composite process measure for venous thromboembolism prophylaxis. Med Care. 2016;54(2):210-217. https://doi.org/10.1097/MLR.0000000000000474.

11. Schünemann HJ, Cushman M, Burnett $A E$, et al. American Society of Hematology 2018 guidelines for management of venous thromboembolism: prophylaxis for hospitalized and nonhospitalized medical patients. Blood Adv. 2018;2(22):3198-3225. https://doi.org/10.1182/bloodadvances.2018022954.

12. Lau BD, Streiff MB, Kraus PS, et al. Missed doses of venous thromboembolism (VTE) prophylaxis at community hospitals: cause for alarm. J Gen Intern Med. 2018;33(1):19-20. https://doi.org/10.1007/s11606-017-4203-y.

13. Elder S, Hobson DB, Rand CS, et al. Hidden barriers to delivery of pharmacological venous thromboembolism prophylaxis: the role of nursing beliefs and practices. J Patient Saf. 2016;12(2):63-68. https://doi.org/10.1097/ PTS.0000000000000086.

14. Lee JA, Grochow D, Drake D, et al. Evaluation of hospital nurses' perceived knowledge and practices of venous thromboembolism assessment and prevention. J Vasc Nurs. 2014;32(1):18-24. https://doi.org/10.1016/j. jvn.2013.06.001.

15. Shermock KM, Lau BD, Haut ER, et al. Patterns of non-administration of ordered doses of venous thromboembolism prophylaxis: implications for novel intervention strategies. PLOS ONE. 2013;8(6):e66311. https://doi. org/10.1371/journal.pone.0066311.

16. Lipworth W, Taylor N, Braithwaite J. Can the theoretical domains framework account for the implementation of clinical quality interventions? BMC Health Serv Res. 2013:13(1):530. https://doi.org/10.1186/1472-6963-13-530.

17. Taylor N, Lawton R, Moore S, et al. Collaborating with front-line healthcare professionals: the clinical and cost effectiveness of a theory based approach to the implementation of a national guideline. BMC Health Serv Res. 2014;14(1):648. https://doi.org/10.1186/s12913-014-0648-4.

18. Cane J, O'Connor D, Michie S. Validation of the theoretical domains framework for use in behaviour change and implementation research. Implement Sci. 2012;7(1):37. https://doi.org/10.1186/1748-5908-7-37.

19. Bogdan R, Biklen S. Qualitative Research for Education: an Introduction to Theory and Methods. Boston: Allyn \& Bacon; 1992.

20. Creswell J. Research Design: Qualitative and Quantitative Approaches. Thousand Oaks, CA: Sage Publications; 1994.

21. Patton M. Qualitative Research \& Evaluation Methods: Integrating Theory and Practice. 4th ed. Thousand Oaks, CA: SAGE Publications, Inc.; 2014.

22. Alexander KE, Brijnath B, Mazza D. Barriers and enablers to delivery of the Healthy Kids Check: an analysis informed by the theoretical domains framework and COM-B model. Implement Sci. 2014;9(1):60. https://doi. org/10.1186/1748-5908-9-60.

23. Birken SA, Presseau J, Ellis SD, Gerstel AA, Mayer DK. Potential determinants of health-care professionals' use of survivorship care plans: a qualitative study using the theoretical domains framework. Implement Sci. 2014;9(1):167. https://doi.org/10.1186/s13012-014-0167-z.

24. Atkins L, Francis J, Islam R, et al. A guide to using the theoretical domains framework of behaviour change to investigate implementation problems. Implement Sci. 2017;12(1):77. https://doi.org/10.1186/s13012-017-0605-9.

25. Lincoln YS, Guba EG. Naturalistic Inquiry. Newbury Park, CA: Sage Publications; 1985.

26. Berlin G. MAXQDA, Software for Qualitative Data Analysis. VERBI Software - Consult. Sozialforschung GmbH [computer program]; 1989-2016.

27. Lipmanowicz H. Buy-in v. ownership. Liberating Structures. http://www.liberatingstructures.com/hl-articles/. Accessed July 5, 2019.

28. Morgan D. Why Should You Use Focus Groups? and what focus groups are (and are not). In: The Focus Group Guidebook. Thousand Oaks, CA: Sage Publications; 1998:9-15, 29-35

29. Sofaer S. Qualitative methods: what are they and why use them? Health Serv Res. 1999;34(5):1101-1118. 